\title{
Identificação inicial de alunos com altas habilidades ou superdotação: avaliação intelectual, de desempenho escolar e indicação pelos professores
}

\author{
Lurian Dionizio Mendonça* \\ Olga Maria Piazentin Rolim Rodrigues** \\ Vera Lúcia Messias Fialho Capellini ${ }^{* * *}$
}

\section{Resumo}

O presente estudo realizou uma identificação inicial de 259 alunos de ensino fundamental com indicadores de Altas Habilidades ou Superdotação (AH/SD) a partir da aplicação do Teste das Matrizes Progressivas Coloridas de Raven, do Teste de Desempenho Escolar (TDE) e da indicação dos professores dos alunos que mais se sobressaiam em sala de aula e em que áreas. Dos alunos, $11,36 \%$ tiveram desempenho muito superior à média no Teste de Raven e 3,86\% deles apresentaram pelo menos dois resultados superiores no TDE. Os professores indicaram 33 alunos e as características mais observadas foram a capacidade de pensamento abstrato - talento científico-matemático e o talento verbal. Para a análise dos alunos com indicadores de AH/SD observou-se pouca concordância entre os instrumentos. Foram, então, identificados 81 alunos com indicativos de AH/SD, que preencheram pelo menos um dos critérios estabelecidos, ou seja, ser classificado dentro do percentil 90 ou mais no Teste de Raven, apresentar pelo menos dois superiores nos subtestes do TDE ou ser indicado por seus professores, para a participação em avaliaçôes mais detalhadas para definição do diagnóstico.

Palavras-chave: Altas habilidades ou superdotação; Identificação; Educação Especial.

\footnotetext{
* Doutoranda em Psicologia do Desenvolvimento e Aprendizagem pela Universidade Estadual Paulista Júlio de Mesquita Filho, Bauru, São Paulo, Brasil.

** Professora Doutora da Universidade Estadual Paulista Júlio de Mesquita Filho, Bauru, São Paulo, Brasil.

*** Professora Doutora da Universidade Estadual Paulista Júlio de Mesquita Filho, Bauru, São Paulo, Brasil.
} 


\section{Identification of students home with high ability or giffedness: intellectual evaluation of school performance and indication by teachers}

\section{Abstract}

This study carried out an initial identification of 259 students from elementary school with indicators of High Ability or Giftedness (AH/SD) from the application of the Test of Colored Progressive Matrices of Raven, the Academic Performance Test (TDE) and the indication of student teachers who most excelled in the classroom and in what areas. Students, $11,36 \%$ were well above average performance in Raven test and 3,86\% of them had at least two superior results in TDE. Teachers indicated 33 students and the most observed characteristics were the abstract thinking ability - talent scientific-mathematical and verbal talent. For the analysis of students with indicators $\mathrm{AH} / \mathrm{SD}$ there was little agreement between the instruments. Were then identified 81 student's indicative of AH/SD, who met at least one of the criteria, i.e. be classified within the 90th percentile or more in the Raven Test, have at least two higher in the subtests of TDE or be indicated by their teachers to participate in more detailed assessments to define the diagnosis.

Keywords: High ability or giftedness; Identification; Special Education.

\section{Introdução}

Os alunos com Altas Habilidades ou Superdotaçáo (AH/SD) são considerados público alvo da Educação Especial, ou seja, com direito a ter um atendimento educacional especializado por se tratar de pessoas que podem necessitar de programas diferenciados de ensino e aprendizagem. As escolas pautadas na Perspectiva da Educação Inclusiva (BRASIL, 2008) devem garantir a possibilidade de aprendizagem de cada aluno, a partir de suas capacidades, aptidóes sem que, qualquer das suas características seja impeditiva para sua frequência neste ambiente. Elas devem, então, dar condiçóes para que ocorra a aprendizagem de todos os alunos, independente de suas características.

A literatura da área tem enfatizado a necessidade de atendimento aos alunos com AH/SD para que o potencial que cada um deles apresenta possa ser desenvolvido (ALENCAR, 2001; FLEITH, 2007; VIRGOLIM, 2007; CUPERTINO, 2008; SABATELLA, 2008) para que, por meio de seus talentos possam contribuir para a nossa sociedade, nas diversas áreas de atuação, podendo ser científica, artística, política, esportiva, entre outras.

A Secretaria Estadual de Educação, de acordo com as Diretrizes Nacionais da Educaçáo Especial (FLEITH, 2007) caracterizam os alunos com AH/SD pelo alto desempenho e/ou elevada potencialidade que eles apresentam em qualquer dos seguintes aspectos, isolados ou combinados. São eles: capacidade intelectual geral, aptidão acadêmica específica, pensamento criativo e/ou produtivo, capacidade de liderança, talento especial para as artes, capacidade psicomotora. 
Piirto (1999) traz uma definição de superdotação focada em cenários escolares, ressaltando que esses indivíduos apresentam elevada capacidade de criar, observar e aprender com grande rapidez e exatidáo. Para essa autora, o QI elevado e o talento podem ir se especializando com o tempo e durante o ciclo de desenvolvimento. Apesar de ainda não existir uma definição unânime entre os vários especialistas desta área, aponta-se para uma definição que reconheça a convergência de várias dimensóes humanas na explicação da superdotação, assim como várias formas de excelência (POCINHO, 2009).

No processo de identificação do aluno com AH/SD devem participar os professores, pais e profissionais de áreas especializadas. Os psicólogos podem contribuir com a aplicação de testes padronizados, para uma verificação da produçáo cognitiva do aluno. Os pais podem ajudar com relatos de desenvolvimento desses alunos e os professores podem contribuir para o levantamento dos dados do processo de aprendizagem, sendo possível identificar o conjunto de necessidades educacionais existentes (BRASIL, 2002). Tendo em vista os professores como atuantes nesse processo, Iorio, Chaves e Anache (2016), assinalaram a importância da formação continuada, que pode melhorar a atuação dos mesmos, tanto nesse processo de identificação, como no direcionamento de estratégias pedagógicas para atuar com esses alunos em sala de aula.

A identificação de pessoas com AH/SD não deve se apoiar em regras fixas, mas precisa acontecer de forma dinâmica e em um processo contínuo, uma vez que, para uma identificação adequada recomenda-se utilizar mais de um dos seguintes meios: testes psicométricos, escalas de características, questionários, observação do comportamento, entrevistas com a família e professores, entre outros (FLEITH, 2007). Escalas e testes não fazem diagnósticos, contudo oferecem importantes indícios a partir dos dados objetivos, que são úteis para avaliação, intervenção e pesquisa (BENCZIK, 2000).

Correia (2007) apresenta um conjunto de problemas verificáveis na identificação das crianças sobredotadas: falta de unanimidade em relação ao conceito e às dimensôes; ênfase na identificação precoce, mais problemática e contestada; procedimentos de identificação pouco eficazes; falta de (in)formação dos técnicos sobre o tema; tabus socioculturais associados; pouco investimento na identificação e na capacidade de atendimento; variabilidade das dimensóes intra e interindividual; enviesamento a favor de certos grupos sociais ou gênero e, fraca sistematização dos programas disponíveis.

Betts e Niehart (1988), delinearam alguns dos efeitos, a longo prazo, em crianças com $\mathrm{AH} / \mathrm{SD}$, que não foram identificadas e apontaram que as consequências são predominantemente negativas. São percebidos sentimentos de frustração, baixa autoestima, isolamento, comportamento social negativo, por exemplo, mostrando como a identificação é o primeiro passo para assegurar que as necessidades educacionais dessas crianças sejam atendidas. O principal motivo pelo qual as crianças com $\mathrm{AH} / \mathrm{SD}$ devem ser identificadas é para que elas possam ter uma educação mais adequada. Como todas crianças, as com AH/SD merecem ser desafiadas, motivadas, 
encorajadas e dada a oportunidade de aprender em um ritmo e profundidade que é apropriado para elas (HANSEN, 1992). Os aspectos sociais e emocionais influenciam fortemente as necessidades educacionais de todas as crianças, mas frequentemente são esquecidos. Whybra (2000) identificou que as principais necessidades das crianças com AH/SD é o reconhecimento de sua capacidade e compreensão de suas necessidades sociais e emocionais.

Para Guenther (2006), diagnosticar crianças com dotação e talento constituise um processo contínuo que, de uma forma geral, implica em uma identificação prévia e, depois, uma avaliação mais detalhada e completa. Ela defende que essa avaliação não pode ser feita somente a partir de valores numéricos, já que existem muitas áreas que não podem ser avaliadas apenas nessa perspectiva, o que faria com que algumas das pessoas que possuem um potencial elevado fossem excluídas. A autora ressalta, ainda, que essa identificação deve ser feita até o $5^{\circ}$ ano escolar, pois nos anos seguintes, "o processo pode ser mais complexo, pela impossibilidade de haver um professor que conheça bem o aluno e o acompanhe, dentro do grupo familiar de pares e colegas e que possa coletar dados de observação direta" (GUENTHER, 2006, p. 98).

Os procedimentos e instrumentos disponíveis para a identificação dos alunos com AH/SD nem sempre são confiáveis e válidos. Porém, diversos estudos têm utilizado diferentes instrumentos e metodologias para identificar essa população (FLEITH, 1999; SIMONETTI; ALMEIDA; GUENTHER, 2010). Mendonça, Mencia e Capellini (2015) ressaltam que, para identificar alunos com AH/SD, deve-se utilizar uma variedade de instrumentos e técnicas, tendo em vista, que o potencial desses indivíduos pode ser expresso de diferentes maneiras.

O desempenho escolar também tem sido consistentemente avaliado. O TDE tem sido utilizado para avaliar as dificuldades de aprendizagem, bem como as facilidades encontradas pelos alunos em contexto escolar. Brito et al. (2012) avaliaram 855 alunos, de seis a 16 anos utilizando o TDE relacionando-o com idade e série. Encontraram relação significativa com idade, mas não com a série. Todavia, os resultados mostram que o TDE é uma medida válida de desempenho escolar. Athayde et al. (2014) e Lucio e Pinheiro (2014), buscaram avaliar as propriedades psicométricas e as evidências de validade do subteste de leitura do TDE. Os estudos mostraram que o teste apresenta evidências de validade, mas que precisa ser atualizado. Knijnik, Giacomoni e Stein (2013) fizeram ainda, um levantamento de publicaçôes científicas que utilizaram o TDE. As autoras verificaram que o teste apresenta relevância, mas sinalizaram a importância da atualização, com correspondência para o ensino fundamental de nove anos.

O desempenho intelectual tem sido avaliado utilizando testes padronizados ou não para a nossa população. Flores-Mendoza et al. (2014) investigaram os parâmetros psicométricos do teste das Matrizes Progressivas de Raven. Eles observaram que o teste mantém sua validade como instrumento de avaliação intelectual, mas apontaram a necessidade de aumentar o grau de complexidade do instrumento. Sisto, Rueda e Bartholomeu (2006) avaliaram à unidimensionalidade do teste, contudo, os 
resultados sugeriram que o instrumento possibilita a interpretação da existência de outra dimensão e, assim, a pontuação total usada por esse instrumento, pode náo ser uma medida suficiente. Pasquali, Wechsler e Bensusan (2002), apresentaram uma validaçáo do Raven para o Brasil e concluíram que esse é um teste adequado para avaliar o raciocínio analógico em crianças de 5 a 11 anos de idade, ainda que ele seja composto por tarefas que apresentam alguma dificuldade para a maioria destas crianças.

A busca ativa por alunos com AH/SD, feita com todos os alunos de uma escola, utilizando testes para avaliar o desempenho intelectual e acadêmico, como o Teste de Raven e o TDE além da indicação feita pelos professores, a partir da proposta de Guenther (1998) pode ser um primeiro passo para a identificação desta população. Apesar de existirem diversas outras áreas de superdotação, optamos por buscar alunos com desempenho intelectual e acadêmico superior pela dificuldade de instrumentos que avaliem as demais áreas, como música, liderança e até mesmo esportes.

O presente estudo pretendeu realizar uma identificação inicial de alunos com sinais de AH/SD na área intelectual e acadêmica, em uma escola pública que atende alunos dos anos iniciais ensino fundamental. Foram objetivos específicos: avaliar o desempenho intelectual e acadêmico de todos os alunos da escola e identificar, junto aos professores, os alunos que julgam ter um desempenho acima da média em sua sala.

\section{Método}

\section{Participantes}

Participaram os 15 professores da escola e 259 alunos que realizaram todas as avaliaçóes, de um total de 288 alunos regularmente matriculados (90\%). Todavia, na Tabela 1 estão descritos os alunos que fizeram pelo menos o Raven (93\%/267). Os demais (7\%) eram alunos faltosos ou em processo de transferência. A média de alunos por sala era de 20,5 alunos, sendo $52,43 \%$ do sexo feminino. Em relaçáo à idade, $23,6 \%(63 / 267)$ tinham seis anos, $22,84 \%(61 / 267)$ tinham sete, $22,1 \%(59 / 267)$ tinham oito e $22,1 \%(59 / 267)$ tinham nove, $8,24 \%$ (22/267) tinham dez e $1,12 \%$ (3/267) tinham entre 11 a 13 anos de idade.

Tabela 1 - Número de alunos avaliados por ano escolar

\begin{tabular}{|c|c|c|c|c|c|c|c|c|c|c|c|}
\hline \multirow{2}{*}{ Ano } & \multicolumn{2}{|c|}{ Sexo } & \multirow{2}{*}{$\begin{array}{c}\text { No de } \\
\text { Alunos }\end{array}$} & \multirow{2}{*}{ Ano } & \multicolumn{2}{|c|}{ Sexo } & \multirow{2}{*}{$\begin{array}{l}\text { No de } \\
\text { Alunos }\end{array}$} & \multirow{2}{*}{ Ano } & \multicolumn{2}{|c|}{ Sexo } & \multirow{2}{*}{$\begin{array}{l}N^{o} \text { de } \\
\text { Alunos }\end{array}$} \\
\hline & $\mathbf{M}$ & $\mathbf{F}$ & & & $\mathbf{M}$ & F & & & $\mathbf{M}$ & $F$ & \\
\hline $1^{\circ} \mathrm{A}$ & 11 & 13 & 24 & $2^{\circ} \mathrm{C}$ & 8 & 6 & 14 & $4^{\circ} \mathrm{B}$ & 10 & 10 & 20 \\
\hline $1^{\circ} \mathrm{B}$ & 10 & 9 & 19 & $3^{\circ} \mathrm{A}$ & 12 & 9 & 21 & $4^{\circ} \mathrm{C}$ & 11 & 11 & 22 \\
\hline $1^{\circ} \mathrm{C}$ & 9 & 11 & 20 & $3^{\circ} \mathrm{B}$ & 6 & 13 & 19 & $5^{\circ} \mathrm{A}$ & 10 & 12 & 22 \\
\hline $2 \circ \mathrm{A}$ & 12 & 14 & 26 & $3^{\circ} \mathrm{C}$ & 8 & 8 & 16 & Subtotal & 31 & 33 & 64 \\
\hline $2^{\circ} \mathrm{B}$ & 10 & 13 & 23 & $4^{\circ} \mathrm{A}$ & 10 & 11 & 21 & \multirow{2}{*}{ Total } & \multirow{2}{*}{127} & \multirow{2}{*}{140} & \multirow{2}{*}{267} \\
\hline Subtotal & 52 & 60 & 112 & Subtotal & 44 & 47 & 91 & & & & \\
\hline
\end{tabular}


Os dados foram coletados nas dependências da escola, sendo ela estadual, que atende alunos dos anos iniciais do ensino fundamental, localizada em um bairro de periferia em uma cidade do interior de São Paulo.

\section{Materiais}

Para avaliar o desempenho intelectual dos alunos, foi utilizado o teste Matrizes Progressivas Coloridas de Raven, Escala Especial. Esse teste foi construído para avaliar os processos intelectuais das crianças, na faixa de 5 a 11 anos. A classificação obtida, de acordo com o manual, pode ser agrupada em: I. Intelectualmente superiorse o escore está no percentil 95 ou acima dele; II. Definitivamente acima da média da capacidade intelectual - se o escore está no percentil 75 ou acima dele; II'. Se o escore está no percentil 90 ou acima dele; III. Intelectualmente médio - se o escore está entre o percentil 25 e 75; III+. Se o escore é maior que a mediana ou percentil 50; III- Se o escore é menor que a mediana; IV. Definitivamente abaixo da média na capacidade intelectual - se o escore está no percentil 25 ou abaixo dele; IV. Se o escore está no percentil 10 ou abaixo dele; V. Intelectualmente deficiente - se o escore está no percentil 5 ou abaixo dele para seu grupo de idade (ANGELINI et al., 1999).

O desempenho acadêmico foi verificado a partir da aplicação do TDE, que é um instrumento psicométrico que avalia capacidades fundamentais para o desempenho escolar, a partir de três subtestes: escrita, aritmética e leitura. Esse teste foi elaborado a partir da realidade brasileira e é utilizado com estudantes de $1^{\mathrm{a}}$ a $6^{\mathrm{a}}$ série do ensino fundamental, que corresponde atualmente do $2^{\circ}$ ao $5^{\circ}$ ano dos anos iniciais do ensino fundamental. No entanto, como utilizou-se o teste para alunos do $1^{\circ}$ ano, foi realizada a correlação entre $1^{\mathrm{o}}$ ano e $1^{\text {a }}$ série e assim sucessivamente, apesar de não corresponderem a mesma idade. O teste propôe três classificaçôes, sendo: Superior $(S)$, Médio (M) e Inferior (I) (STEIN, 1994).

Para identificar, junto aos professores, os alunos que eles julgam ter um desempenho acima da média utilizou-se o protocolo "Lista de itens para observaçáo em sala de aula" (GUENTHER, 1998), desenvolvido para o Centro para o Desenvolvimento do Potencial e Talento - CEDET. O instrumento consta de 25 itens de observação, distribuídos aleatoriamente, abrangendo indicadores dos domínios e áreas de capacidade e descrevendo características associadas às áreas específicas. O professor deve preencher um questionário para cada sala de aula, indicando os alunos que mais se sobressaem em cada um dos itens. Os questionários são processados de acordo com o critério de avaliação apresentado no Quadro 1, surgindo dali uma lista de alunos que apresentam os sinais de $\mathrm{AH} / \mathrm{SD}$, dentro das diversas áreas específicas. 
Quadro 1 - Critérios para avaliar os sinais de talento

\begin{tabular}{|c|c|c|}
\hline Áreas Específicas & Itens avaliados & Critério \\
\hline \multirow{2}{*}{ Capacidade e inteligência geral } & $\begin{array}{c}4,6,9,10,11,12,17,18 \\
21,22 \text { e } 25\end{array}$ & $\begin{array}{c}\text { Apresentar pelo menos } 6 \\
\text { itens }\end{array}$ \\
\hline & $9,11,13,17,18,22$ e 25 & $\begin{array}{l}\text { Apresentar pelo menos } 4 \\
\text { itens }\end{array}$ \\
\hline Talento verbal & $1,5,7,18$ e 22 & $\begin{array}{c}\text { Apresentar pelo menos } 3 \\
\text { itens }\end{array}$ \\
\hline $\begin{array}{l}\text { Capacidade de pensamento abstrato } \\
\text { (talento científico-matemático) }\end{array}$ & $2,9,11,18,20$ e 22 & Presença de 3 ou mais itens \\
\hline $\begin{array}{c}\text { Criatividade acentuada e/ou talento } \\
\text { artístico }\end{array}$ & $3,8,10,13,17$ e 25 & $\begin{array}{l}\text { Presença de pelo menos } 4 \\
\text { itens ou } 3 \text { incluindo o } \mathrm{n}^{\circ} \\
3 \text { e } 13\end{array}$ \\
\hline Talento psicossocial & $4,7,14,15,16,19$ e 26 & $\begin{array}{c}\text { Apresentar pelo menos } 4 \\
\text { itens }\end{array}$ \\
\hline Talento psicomotor & 4,23 e 24 & Presença de todos os itens \\
\hline
\end{tabular}

\section{Procedimento para a coleta de dados}

No intuito de atingir as metas propostas, o trabalho foi realizado por meio de etapas. A $1^{a}$ etapa consistiu na aplicação do teste das Matrizes Progressivas Coloridas, que foi realizada de forma coletiva, com aproximadamente cinco ou seis alunos em cada sessão. A $2^{\text {a }}$ etapa versou sobre a aplicação do TDE, que foi realizada de forma individual. As duas avaliaçóes ocorreram no período de aula, com o consentimento da direção da escola e dos pais. Elas duravam em média 20 minutos cada. Por fim, os professores foram convidados e orientados, em Aulas de Trabalho Pedagógico Coletivo (ATPCs) (SÃO PAULO, 2014) para o preenchimento do protocolo de indicação dos alunos que se sobressaem na sala de aula, a partir da Lista de itens para observação.

\section{Procedimento de análise de dados}

Os instrumentos padronizados (Raven e TDE) foram corrigidos e analisados de acordo com as instruçóes dos seus manuais. Os dados foram analisados separadamente, sendo primeiramente identificados os alunos que apresentaram um desempenho no teste das Matrizes Progressivas dentro do percentil 90 ou mais, os alunos que apresentaram dois ou mais resultados superiores nos subtestes do TDE e foi realizado o levantamento dos alunos indicados por seus professores, conforme o proposto pelo instrumento e listadas as características assinaladas pelos seus professores.

\section{Resultados e discussão}

Para este estudo, foram aplicados nos alunos o Teste de Raven e o TDE, sendo 267 alunos com o primeiro instrumento e 259 com o segundo. A diferença de dados se deve à faltas e mudanças de escola no meio do processo. 
Apesar de haver críticas quanto ao uso de testes para identificar pessoas com AH/SD, a aplicação do Teste de Raven e do TDE se deu para serem utilizados como uma medida inicial, ou seja, um instrumento de triagem, para realizar um levantamento dos alunos com possíveis sinais de $\mathrm{AH} / \mathrm{SD}$. Esses instrumentos são úteis para esta finalidade por serem de fácil e rápida aplicação (PASQUALI; WECHSLER; BENSUSAN, 2002; TENORIO; AVILA, 2012; KNIJNIK; GIACOMONI; STEIN, 2013; FLORES-MENDOZA, et al., 2014).

A Tabela 2 apresenta os dados obtidos no Teste de Raven. Dos alunos que fizeram o teste, $11,61 \%(31 / 267)$ foram considerados intelectualmente superiores (Percentil 95 ou mais); 26,97\% (72/267) foram considerados acima da média da capacidade intelectual (Percentil de 75 a 94); 46,82\% (125/267) foram considerados intelectualmente médios (Percentil de 25 a 74); 13,48\% (36/267) foram considerados definitivamente abaixo da média (Percentil abaixo de 24$) ; 0,37 \%$ (1/267) foram considerados intelectualmente deficientes e, $0,75 \%(2 / 267)$ tinham a idade superior ao proposto no instrumento. Neste trabalho estabeleceu-se o critério de percentil 90 ou mais para considerar o aluno intelectualmente superior, resultando em 59 $(22,1 \%)$ alunos que preencheram o critério. Observa-se que, dentro do esperado, a maioria dos alunos $(46,82 \%)$ apresentou desempenho intelectual dentro da média. Gonçalves e Fleith (2011) utilizaram o Raven para avaliar crianças indicadas ou não como superdotadas pelos seus professores e o resultado apontou que o teste foi sensível ao comprovar o alto QI das crianças indicadas.

Tabela 2 - Classificação no teste das matrizes progressivas coloridas de Raven

\begin{tabular}{|c|c|c|c|}
\hline Classificaçáo & Percentil & $\mathbf{N}$ & $\%$ \\
\hline $\begin{array}{l}\text { Intelectualmente } \\
\text { superior }\end{array}$ & 95 ou mais & 31 & 11,61 \\
\hline \multirow{2}{*}{$\begin{array}{l}\text { Definitivamente } \\
\text { acima da média }\end{array}$} & 90 ou mais & 28 & 10,49 \\
\hline & 75 ou mais & 44 & 16,48 \\
\hline \multirow{3}{*}{$\begin{array}{l}\text { Intelectualmente } \\
\text { médio }\end{array}$} & Mais de 50 & 70 & 26,22 \\
\hline & Entre 25 e 75 & 9 & 3,37 \\
\hline & Menos de 50 & 46 & 17,23 \\
\hline \multirow{2}{*}{$\begin{array}{l}\text { Definitivamente } \\
\text { abaixo da média }\end{array}$} & 25 ou menos & 26 & 9,74 \\
\hline & 10 ou menos & 10 & 3,74 \\
\hline $\begin{array}{l}\text { Intelectualmente } \\
\text { deficiente }\end{array}$ & 5 ou menos & 1 & 0,37 \\
\hline Idade acima do teste & - & 2 & 0,75 \\
\hline \multicolumn{2}{|c|}{ Total } & 267 & 100 \\
\hline
\end{tabular}


Os resultados obtidos no TDE, apresentados na Tabela 3, mostraram que no subteste de escrita 1,93\% (5/259) foram classificados como superiores; $25,87 \%$ (67/259) como médios e 72,20\% (187/259) como inferiores. No subteste de aritmética, 1,16\% (3/259) foram classificados como superiores, 16,60\% (43/259) como médios e $82,24 \%$ (213/259) como inferiores. No subteste de leitura 15,45\% (40/259) foram classificados como superiores, 27,41\% (71/259) como médios e $57,14 \%$ (148/259) como inferiores. Na classificação total 1,55\% (4/259) obtiveram o resultado superior, 19,69\% (51/259) médio e 78,76\% (204/259) inferior. Os resultados confirmam os obtidos por Dias, Enumo e Turini (2006) que encontraram índices mais altos de desempenho inferior nos alunos avaliados e ainda, os de Tenório e D'Avila (2012) que encontraram melhor desempenho em leitura do que nos demais subtestes.

Tabela 3 - Classificaçáo no teste de desempenho escolar

\begin{tabular}{|c|c|c|c|c|c|c|c|c|}
\hline \multirow{3}{*}{ Classificação } & \multicolumn{8}{|c|}{ Subteste } \\
\hline & \multicolumn{2}{|c|}{ Escrita } & \multicolumn{2}{|c|}{ Aritmética } & \multicolumn{2}{|c|}{ Leitura } & \multicolumn{2}{|c|}{ Total } \\
\hline & $\mathbf{N}$ & $\%$ & $\mathbf{N}$ & $\%$ & $\mathbf{N}$ & $\%$ & $\mathbf{N}$ & $\%$ \\
\hline Superior & 5 & 1,93 & 3 & 1,16 & 40 & 15,45 & 4 & 1,55 \\
\hline Médio & 67 & 25,87 & 43 & 16,60 & 71 & 27,41 & 51 & 19,69 \\
\hline Inferior & 187 & 72,20 & 213 & 82,24 & 148 & 57,14 & 204 & 78,76 \\
\hline Total & 259 & 100 & 259 & 100 & 259 & 100 & 259 & 100 \\
\hline
\end{tabular}

Dentre os alunos que realizaram o TDE, 3,86\% (10/259) atingiram o critério proposto, que era obter pelo menos dois superiores nos subtestes, incluindo o geral. Destes, todos (100\%) tinham um superior em leitura e o outro dividido nos demais subtestes, sendo que 50\% (5/10) obtiveram um superior no subteste de escrita, 30\% (3/10) no subteste de aritmética e 40\% (4/10) no total, conforme descrito na Tabela 4.

Tabela 4 - Classificação dos alunos que obtiveram dois superiores ou mais no TDE

\begin{tabular}{|c|c|c|c|c|c|c|c|c|}
\hline \multirow{3}{*}{ Classificaçáo } & \multicolumn{8}{|c|}{ Subteste } \\
\hline & \multicolumn{2}{|c|}{ Escrita } & \multicolumn{2}{|c|}{ Aritmética } & \multicolumn{2}{|c|}{ Leitura } & \multicolumn{2}{|c|}{ Total } \\
\hline & $\mathbf{N}$ & $\%$ & $\mathbf{N}$ & $\%$ & $\mathbf{N}$ & $\%$ & $\mathbf{N}$ & $\%$ \\
\hline Superior & 5 & 50 & 3 & 30 & 10 & 100 & 4 & 40 \\
\hline Médio & 3 & 30 & 3 & 30 & - & - & 5 & 50 \\
\hline Inferior & 2 & 20 & 4 & 40 & - & - & 1 & 10 \\
\hline Total & 10 & 100 & 10 & 100 & 10 & 100 & 10 & 100 \\
\hline
\end{tabular}


Os professores indicaram os alunos que eles julgavam ter um desempenho acima da média, na Lista de itens para observação em sala de aula, sendo que eles apontaram, no total, 194 alunos. No entanto, de acordo com o critério descrito no Quadro 1, somente 33 alunos atenderam aos critérios. Guenther (2006) prefere a indicação do professor como indispensável para a identificação de alunos com $\mathrm{AH} /$ $\mathrm{SD}$, desde que devidamente capacitados para tal, por acompanharem diariamente o desenvolvimento de seus alunos, do que a utilização de instrumentos que tem resultados numéricos. Todavia, estudos foram encontrados questionando a indicaçáo dos professores, sugerindo que as mesmas devem ser vistas com cautela devido ao pouco conhecimento que eles têm mostrado sobre a questão da superdotação, ainda carregada de mitos (MAIA-PINTO; FLEITH, 2002; RECH; FREITAS, 2005).

A Tabela 5 mostra os resultados das indicaçôes dos professores. Dos 33 alunos que atenderam aos critérios da Lista de itens para observação em sala de aula, 63,64\% (21/33) apresentaram somente uma característica específica e as demais apresentaram de duas ou mais características, totalizando assim, 63 características que estão divididas nas seis áreas específicas, sendo que, 14,29\% (9/63) correspondem a capacidade e inteligência geral; $22,22 \%(14 / 63)$ ao talento verbal; $34,92 \%(22 / 63)$ a capacidade de pensamento abstrato (talento científico-matemático); $15,87 \%(10 / 63)$ a criatividade acentuada e/ou talento artístico; 11,11\% (7/63) ao talento psicossocial e, 1,59\% (1/63) com o talento psicomotor.

Tabela 5 - Número de alunos indicados nas respectivas áreas específicas

\begin{tabular}{|c|c|c|}
\hline Áreas específicas & $\mathbf{N}$ (de indicaçóes) & $\%$ \\
\hline $\begin{array}{c}\text { Capacidade e inteligência } \\
\text { geral }\end{array}$ & 9 & 14,29 \\
\hline Talento verbal & 14 & 22,22 \\
\hline $\begin{array}{c}\text { Capacidade de pensamento } \\
\text { abstrato }\end{array}$ & 22 & 34,92 \\
\hline $\begin{array}{c}\text { Criatividade acentuada e/ou } \\
\text { talento artístico }\end{array}$ & 10 & 15,87 \\
\hline Talento psicossocial & 7 & 11,11 \\
\hline Talento psicomotor & 1 & 1,59 \\
\hline Total & 63 & 100 \\
\hline
\end{tabular}

Como os resultados do TDE foram abaixo do esperado e houve pouca concordância entre os demais instrumentos, optou-se por considerar com indicativos de $\mathrm{AH} / \mathrm{SD}$ aqueles que preenchessem pelo menos um dos critérios resultando, em $30,33 \%(81 / 267)$ dos alunos considerados com AH/SD, sendo que somente 2,47\% (2/81) obtiveram os resultados desejados nos três instrumentos (Teste de Raven, TDE e indicação do professor). Cerca de 20,88\% (17/81) dos alunos preencheram pelo menos dois dos critérios, 3,70\% (3/81) no Teste de Raven e no TDE, 12,34\% 
(10/81) no Teste de Raven e foram indicados pelos professores e, 4,94\% (4/81) pelo TDE e pela indicação dos professores. Dos demais, 54,32\% (44/81) apresentam indicadores somente com o Teste de Raven, 1,23\% (1/81) com o TDE e, 21\% (17/81) com a indicação dos professores, conforme a Tabela 6.

Tabela 6 - Número de alunos considerados com indicadores de AH/SD, no conjunto de instrumentos

\begin{tabular}{|c|c|c|}
\hline Instrumento & $\mathbf{N}$ & $\mathbf{\%}$ \\
\hline $\begin{array}{c}\text { Teste de Raven, TDE e } \\
\text { Indicação do professor }\end{array}$ & 2 & 2,47 \\
\hline Teste de Raven e TDE & 3 & 3,70 \\
\hline $\begin{array}{c}\text { Teste de Raven e Indicação } \\
\text { do professor }\end{array}$ & 10 & 12,34 \\
\hline $\begin{array}{c}\text { TDE e Indicação do } \\
\text { professor }\end{array}$ & 4 & 4,94 \\
\hline Teste de Raven & 44 & 54,32 \\
\hline TDE & 17 & 1,23 \\
\hline Indicação do professor & 81 & 21 \\
\hline Total & & 100 \\
\hline
\end{tabular}

Observa-se que os instrumentos não apresentaram concordância, uma vez que, ao cruzar os resultados só obteríamos 2,47\% (2/81) dos alunos com esse indicativo de AH/SD, sendo que, o Teste de Raven teve mais relaçáo com a indicação do professor do que com o desempenho no TDE, que avalia o desempenho acadêmico. Soares, Arco-Verde e Baibich (2004) consideram que o desempenho escolar, aqui avaliado com o TDE, pode estar associado com o que a escola oferece. Os resultados sugerem que a escola pesquisada apresenta possíveis deficiências pedagógicas, um fato que ocorre nas demais escolas brasileiras, mostrado pelo Saeb (Sistema de Avaliaçáo da Educação Básica), cujos resultados de nível básico, apontam que os estudantes apresentam apenas o domínio mínimo dos conteúdos acadêmicos esperados.

Nota-se, pelo resultado no Teste de Raven, que os alunos não apresentam baixo desempenho intelectual, mas seu desempenho acadêmico está muito abaixo do que seriam realmente capazes se fossem expostos a condiçóes de ensino ideais. Guenther (2000) defende que o desempenho escolar não pode ser descartado como um indicativo de AH/SD, "pois essa também é uma área de produção, onde a criança pode expressar suas capacidades” (GUENTHER, 2000, p. 96). Contudo, apesar de existir pessoas com AH/SD nas diferentes classes sociais (CHAGAS, 2003; GUENTHER, 2000, 2006; PÉREZ, 2004, 2008), o desempenho escolar sofre os efeitos das carências socioeconômicas como, por exemplo, a mudança constante de escolas e falta de acesso a recursos culturais, como livros, teatro, cinema, museus etc. (PÉREZ, 2013).

Dentre as 81 crianças com indicadores iniciais para AH/SD, 59,26\% (48/81) são do sexo masculino e o restante, $40,74 \%$ (33/81) do sexo feminino. Em rela- 
ção à idade, $18,52 \%(15 / 81)$ tem seis anos, $20,99 \%$ (17/81) sete, 30,86\% (25/81) oito, $22,22 \%(18 / 81)$ nove e $7,41 \%(6 / 81) 10$ anos ou mais. Quanto ao ano escolar $18,52 \%(15 / 81)$ estavam matriculados no $1^{\circ}$ ano, $23,46 \%(19 / 81)$ no $2^{\circ}$ ano, $27,15 \%(22 / 81)$ no $3^{\circ}$ ano, $23,46 \%(19 / 81)$ no $4^{\circ}$ ano e $7,41 \%(6 / 81)$ no $5^{\circ}$ ano, conforme descritos na Tabela 7.

Tabela 7 - Dados de sexo, idade e série dos alunos com indicadores iniciais para AH/SD

\begin{tabular}{|c|c|c|}
\hline Dados & $\mathbf{N}$ & $\%$ \\
\hline \multicolumn{3}{|c|}{ Sexo } \\
\hline Masculino & 48 & 59,26 \\
\hline Feminino & 33 & 40,74 \\
\hline \multicolumn{3}{|c|}{ Idade } \\
\hline 6 anos a 6 anos e 11 meses & 15 & 18,52 \\
\hline 7 anos a 7 anos e 11 meses & 17 & 20,99 \\
\hline 8 anos a 8 anos e 11 meses & 25 & 30,86 \\
\hline 9 anos a 9 anos e 11 meses & 18 & 22,22 \\
\hline 10 anos ou mais & 6 & 7,41 \\
\hline \multicolumn{3}{|c|}{ Ano Escolar } \\
\hline $1^{\circ}$ ano & 15 & 18,52 \\
\hline $2^{\circ}$ ano & 19 & 23,46 \\
\hline $3^{\circ}$ ano & 22 & 27,15 \\
\hline $4^{\mathrm{o}}$ ano & 19 & 23,46 \\
\hline $5^{\circ}$ ano & 6 & 7,41 \\
\hline
\end{tabular}

Fonseca (2010) identificou seis alunos com AH/SD em uma escola da rede particular de ensino de Teresina, Piauí. Desses alunos, 83,33\% (5/6) eram do sexo masculino. Ainda que não tão discrepantes em nossa pesquisa, também foi identificado um número maior de meninos. Apesar da pesquisa de Fonseca (2010) ter sido realizada com alunos do $3^{\circ}$ ao $5^{\circ}$ ano, foram identificados mais alunos, 50\% (3/6), matriculados no $3^{\circ}$ ano, repetindo os resultados obtidos em nossa pesquisa.

\section{Considerações finais}

De acordo com Moscoso e Rodríguez (2005), para realizar uma identificação com os menores erros possíveis, deve-se fazê-la em duas fases, uma de triagem e outra de diagnóstico. $\mathrm{O}$ presente estudo teve como objetivo realizar a triagem inicial para identificar alunos com possíveis sinais de AH/SD nas áreas acadêmica e intelectual. Com o intuito de realizar uma avaliação com mais eficácia, foram utilizados dois 
testes padronizados, além de um protocolo de identificação respondido pelos professores. Tal decisão se pautou na tentativa de garantir uma identificação mais adequada, visto que, um instrumento pode ser mais sensível à avaliação de um componente que o outro em uma determinada situação ou contexto, assim como tem sido enfatizado por diversos autores (RENZULLI; REIS, 1985; GONÇALVES, 2010; PÉREZ, 2013). Os autores ressaltam a importância de se realizar uma avaliação abrangente e multidimensional, englobando diversos instrumentos.

Entre os instrumentos escolhidos, observa-se que o TDE apontou para a fragilidade do ensino oferecido, mostrando que mesmo os alunos bastante inteligentes estáo defasados em termos de conteúdos quanto ao ano escolar em que estáo matriculados.

Percebe-se, ainda, que a identificação de AH/SD é algo possível, que pode ser feito nas escolas, através da própria indicação dos professores, associado ao uso de testes que podem ser aplicados facilmente com todos os alunos da escola, como o realizado no presente estudo. Observou-se que nenhuma das medidas foi suficientemente boa para avaliar o desempenho dos alunos, apontando para a importância de uma avaliação multimodal e da confirmação desses dados, ou seja, de um diagnóstico mais preciso.

Enfim, considera-se importante que essa identificação seja realizada, pois o conhecimento das características e necessidades do aluno com AH/SD, que resultam de um bom processo de identificação pode ajudar a planejar uma série de medidas condizentes com as demandas e necessidades desses sujeitos (TOURÓN; REYERO; FERNÁNDEZ, 2009). Mesmo que alguns alunos sejam erroneamente identificados, por exemplo, um aluno que tem inteligência acima da média, mas náo está dentro do critério de $\mathrm{AH} / \mathrm{SD}$, um atendimento especializado para ele não será em vão, pois terá de alguma forma, as suas necessidades educacionais atendidas. Este aparente equívoco é melhor do que ter alunos com AH/SD que não foram identificados, tornando-o marginalizado no processo de ensino, já que não têm o estímulo necessário para o desenvolvimento do seu talento. $O$ resultado deste estudo culminou na contratação de um professor especialista para o desenvolvimento de açóes junto à população identificada, o primeiro no Estado de Sáo Paulo. Esperamos que estudos como este sensibilizem as escolas para a identificação de alunos com indicadores de AH/SD, visando proporcionar a eles uma educação que atenda às suas habilidades e interesses, por meio do enriquecimento curricular.

\section{Referências}

ALENCAR, E. S. Criatividade e educaçáo de superdotados. Petrópolis: Vozes, 2001.

ANGELINI, A. L. et al. Matrizes Progressivas Coloridas de Raven: Escala Especial. Manual. São Paulo: Centro Editor de Testes e Pesquisas em Psicologia, 1999.

ATHAYDE, M. L. et al. Evidências de validade do subteste de leitura do teste de desempenho escolar. Psicologia: teoria e prática, v. 16, n. 2, p. 131 - 140, 2014.

BENCZIK, E. B. P. Transtorno de déficit de atenção/hiperatividade: Atualização diagnóstica e terapêutica. Sáo Paulo: Casa do Psicólogo, 2000.

BETTS, G. T.; NIEHART, M. Profiles of the gifted and talented. Gifted Child Quarterly, v. 32, n. 2, p. 248 $-251,1988$. 
BRASIL. Ministério da Educação e Cultura. Secretaria de Educação Especial. Projeto Escola Viva. Garantindo o acesso e permanência de todos os alunos na escola. Alunos com necessidades educacionais especiais. Brasília: MEC/SEESP, 2002.

. Ministério da Educação. Secretaria de Educação Especial. Política Nacional de Educaçáo Especial na Perspectiva da Educaçáo Inclusiva. Brasília: MEC/ SEESP, 2008.

BRITO, L. O. et al. Relação das variáveis idade e escolaridade com desempenho escolar de estudantes de ensino fundamental. Avaliaçáo Psicológica, v. 11, n. 1, p. 83 - 93, 2012.

CHAGAS, J. F. Características familiares relacionadas ao desenvolvimento de comportamentos de superdotação em alunos de nível socioeconômico desfavorecido. 2003. 179f. Dissertação (Mestrado em Psicologia Escolar e Desenvolvimento) - Instituto de Psicologia, Universidade de Brasília, Brasília, 2003.

CORREIA, C. A criança sobredotada. 2007. Disponível em: <http://pt.scribd.com/doc/48810883/2-ANEIS>. Acesso em: 14 jul. 2014.

CUPERTINO, C. M. B. (Org.). Um olhar para as altas habilidades: Construindo caminhos. São Paulo (Estado) Secretaria da Educação, CENP/CAPE. São Paulo: FDE, 2008.

DIAS, T. L.; ENUMO, S. R. F.; TURINI, F. A. Avaliação do desempenho acadêmico de alunos do ensino fundamental em Vitória, Espírito Santo. Estudos de Psicologia, v. 23, n. 4, p. 381 - 390, 2006.

FLEITH, D. S. Psicologia e Educação do superdotado: Definição, sistema de identificação e modelo de estimulação. Cadernos de Psicologia da SBP, v. 5, n. 1, p. 37 - 50, 1999.

FLORES-MENDOZA, C. et al. Propriedades psicométricas do Raven Geral no contexto de Minas Gerais. Arquivos Brasileiros de Psicologia, v. 66, n. 2, p. 1 - 16, 2014.

FONSECA, D. F. A identificaçáo de alunos com altas habilidades/superdotaçáo em uma escola da rede particular de ensino de Teresina-Piauí. 2010. 110f. Dissertação (Mestrado em Educaçáo). Universidade Federal do Piauí, 2010.

GONÇALVES, F. C. Estudo comparativo entre alunos superdotados e náo-superdotados em relaçáa à criatividade, inteligência e percepçáo de clima em sala de aula. 2010. 91 f. Dissertação (Mestrado em Processos de Desenvolvimento Humano e Saúde). Universidade de Brasília, Instituto de Psicologia, 2010.

GONÇALVES, F. C.; FLEITH, D. S. Estudo comparativo entre alunos superdotados e não-superdotados em relaçáo à inteligência e criatividade. PsiCO, v. 42, n. 2, p. 263 - 268, 2011.

GUENTHER, Z. C. Capacidade e talento: Um programa para a escola. São Paulo: EPU, 2006.

Desenvolver capacidades e talentos: Um conceito de inclusão. Petrópolis, RJ: Vozes, 2000. 1998.

Identificaçáo do talento pela observaçáo direta. Lavras, MG: Relatório de pesquisa da FAPEMIG,

HANSEN, J. B. Discovering highly gifted students. Understanding Our Gifted, v. 4, n. 4, p. 23 - 25, 1992.

IORIO, N. M.; CHAVES, F. F.; ANACHE, A. A. Revisão de literatura sobre aspectos das avaliaçóes para Altas Habilidades/Superdotaçáo. Revista Educação Especial, v. 29, n. 55, p. 413 - 428, 2016.

KNIJNIK, L. F.; GIACOMONI, C.; STEIN, L. M. Teste de Desempenho Escolar: um estudo de levantamento. Psico-USF, v. 18, n. 3, p. 407 - 416, 2013.

LUCIO, P. S.; PINHEIRO, A. M. V. Novos estudos psicométricos para o subteste de leitura do teste de desempenho escolar. Temas em Psicologia, v. 22, n. 1, p. 109 - 119, 2014.

MAIA-PINTO, R. R.; FLEITH, D. S. Percepção de professores sobre alunos superdotados. Revista Estudos de Psicologia, v. 19, n. 1, p. 78 - 90, 2002.

MENDONÇA, L. D.; MENCIA, G. F. M.; CAPELLINI, V. L. M. F. Programas de enriquecimento escolar para alunos com altas habilidades ou superdotação: análise de publicaçóes brasileiras. Revista Educaçáo Especial, v. 28, n. 53, p. $721-734,2015$.

MOSCOSO, M. Y. R.; RODRÍGUEZ, J. L. R. La identificación de alumnos con superdotación intelectual. En: V Congreso Internacional Virtual de Educación (CIVE). Universidad de Vigo, Ourense - España, 2005. PASQUALI, L.; WECHSLER, S.; BENSUSAN, E. Matrizes Progressivas do Raven Infantil: um estudo de validação para o Brasil. Avaliaçáo Psicológica, v. 1, n. 2, p. 95 - 110, 2002.

PÉREZ, S. G. P. B. Encontros e desencontros na identificação dos indicadores de Altas Habilidades/Superdotação. Psicologia Argumento, v. 31, n. 72, p. 57 - 78, 2013. 
PÉREZ, S. G. P. B. Gasparzinho vai à escola: Um estudo das características do aluno com altas habilidades produtivo-criativo. 2004. 306f. Dissertação (Mestrado em Educação) - Faculdade de Educação da Pontifícia Universidade Católica do Rio Grande do Sul (PUCRS), Porto Alegre, 2004.

Ser ou náo ser, eis a questáo: $\mathrm{O}$ processo de construçấo da identidade na Pessoa com Altas Habilidades/Superdotação adulta. 2008. 230f. Tese (Doutorado em Educação) - Faculdade de Educação da Pontifícia Universidade Católica do Rio Grande do Sul (PUCRS), Porto Alegre, 2008.

PIIRTO, J. Talented children and adults: Their development and education. Columbus, Pretice Hall/Merril, 1999.

POCINHO, M. Superdotação: conceitos e modelos de diagnóstico e intervençẫo psicoeducativa. Revista brasileira de educaçáo especial, v. 15, n. 1, p. 3 - 14, 2009.

RECH, A. J. D.; FREITAS, S. N. O papel do professor junto ao aluno com Altas Habilidades. Cadernos de Educação Especial, n. 25, p. 1 - 7, 2005.

RENZULLI, J. S.; REIS, S. M. The schoolwide enrichment model: A comprehensive plan for education excellence. Mansfield Center, CT: Creative Learning, 1985.

SABATELLA, M. L. P. Talento e superdotaçáo: Problema ou soluçâa? Curitiba: Ibpex, 2008.

SÃO PAULO (Estado). Secretaria de Educação. Resoluçáo SE No 70/2014, de 29 de dezembro de 2014. Altera dispositivos da Resolução SE No 75/2013. São Paulo, 2014.

SIMONETTI, D. C.; ALMEIDA, L. S.; GUENTHER, Z. Identificaçâo de alunos com altas capacidades: Uma contribuição de indicadores neuropsicológicos. Revista Educaçáo Especial, v. 23, n. 36, p. 43 - 56, 2010.

SISTO, F. F.; RUEDA, F. J. M.; BARTHOLOMEU, D. Estudo sobre a unidimensionalidade do Teste Matrizes Progressivas Coloridas de Raven. Psicologia: Reflexão e Crítica, v. 19, n. 1, p. 66 - 73, 2006.

SOARES, A. M. I.; ARCO-VERDE, Y. F. S.; BAIBICH, T. M. Superdotação: Identificação e opçôes de atendimento. Educar, n. 23, p. 125 - 141, 2004.

STEIN, L. M. TDE: Teste de Desempenho Escolar: Manual para aplicação e interpretação. São Paulo: Casa do Psicólogo, 1994.

TENORIO, S. M. P. C. P; AVILA, C. R. B. Processamento fonológico e desempenho escolar nas séries iniciais do ensino fundamental. Revista CEFAC, v. 14, n. 1, p. 30 - 38, 2012.

TOURÓN, J.; REYERO, M.; FERNÁNDEZ, R. La superdotación en el aula: claves para su identificación y tratamiento educativo. In: BAUTISTA GARCÍA-VERA, A. (Coord.). Formación de profesores de educación secundaria. Programación y Evaluación curricular. Madrid: ICE, Universidad Complutense, 2009.

VIRGOLIM, A. M. R. (Org.). Altas habilidade/superdotação: encorajando potenciais. Brasília: Ministério da Educação, Secretaria de Educaçáo Especial, 2007.

WHYBRA, J. Extension and enrichment programmes: a place I could fit in. In: STOPPER, M. J. (Ed). Meeting the social and emotional needs of gifted and talented children, London, David Fulton Publishers, p. $99-118,2000$.

\section{Correspondência}

Olga Maria Piazentin Rolim Rodrigues - Universidade Estadual Paulista Júlio de Mesquita Filho, Faculdade de Ciências de Bauru, Departamento de Psicologia. Avenida Luiz Edmundo Carrijo Coube, s/n. Vargem Limpa - CEP: 17033-360. Bauru, Sáo Paulo, Brasil.

E-mail: luriandmendonca@gmail.com - olgarolim@fc.unesp.br - verinha@fc.unesp.br

Recebido em 23 de setembro de 2016

Aprovado em 13 de janeiro de 2017 
